\title{
Gel immersion endoscopic mucosal resection for early gastric cancer near the pyloric ring
}

Achieving complete resection of gastric tumors near the pyloric ring with conventional endoscopic mucosal resection (EMR) or endoscopic submucosal dissection is challenging. Limited working space, inadequate assessment of the distal margin, and peristaltic movements result in incomplete resection and/or a long procedure time. Underwater EMR has been recently reported to be effective for treating colorectal and duodenal epithelial neoplasms [1,2]. Although earlier reports described gastric underwater EMR [3], it is sometimes difficult to accumulate and maintain sufficient water in the pylorus. Herein we present a case of early gastric cancer near the pyloric ring treated with gel immersion EMR.

A 73-year-old man underwent esophagogastroduodenoscopy at our hospital, which revealed a 12-mm protruded lesion at the anterior wall of the pylorus (॰ Fig.1). Magnifying endoscopy with narrow-band imaging revealed an irregular microsurface and microvascular patterns suggestive of early gastric cancer ( Fig.2). We initially attempted underwater EMR; however, water flowed out through the pyloric ring and the tumor could not be submerged. Therefore, we performed gel immersion EMR using Viscoclear (Otsuka Pharmaceutical Factory, Tokushima, Japan), a gel-based product ( $\triangleright$ Video $\mathbf{1})$. The injected gel remained in the lesion, provided sufficient buoyancy and a clear endoscopic visual field, and maintained pyloric lumen dilation, allowing us to easily confirm the margin and snare the lesion. We successfully achieved en-bloc resection ( Fig.3, $>$ Fig.4), and total procedure time was 2 minutes. Histopathological diagnosis was well-differentiated intramucosal adenocarcinoma with negative lateral and vertical margins ( $\mathbf{F i g . 5}$ ).

The usefulness of gel immersion EMR for a colonic tumor extending to the diverti-

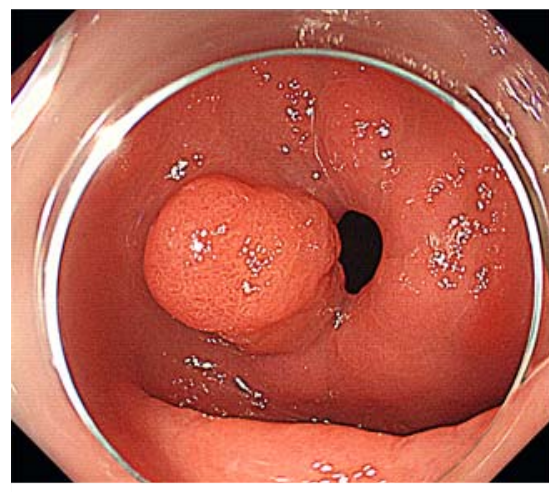

- Fig. 1 Endoscopic image of the gastric tumor near the pyloric ring.

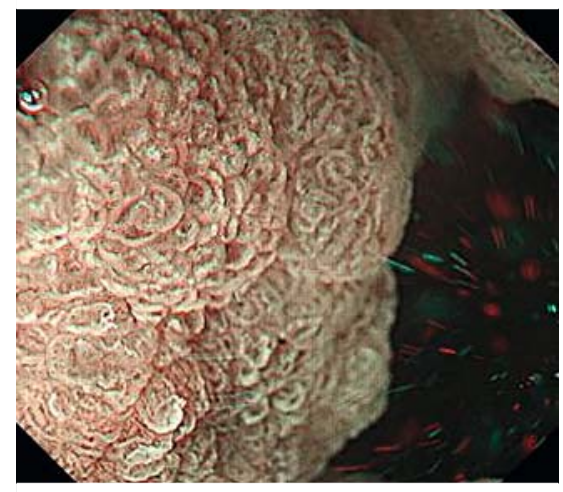

- Fig. 2 Endoscopic image of the gastric tumor observed by magnifying endoscopy with narrow-band imaging under gel immersion.

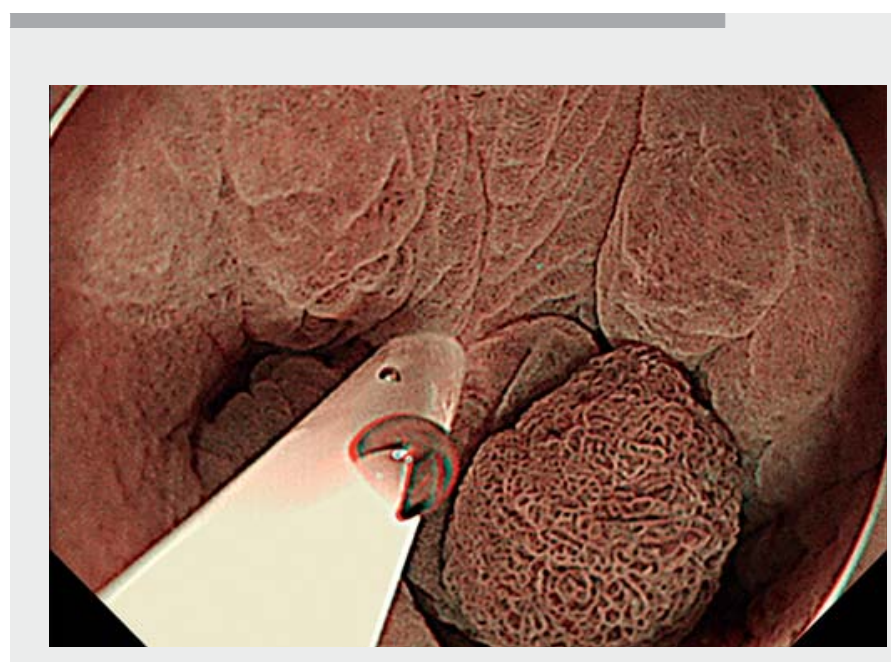

Video 1 The procedure of gel immersion endoscopic mucosal resection for early gastric cancer near the pyloric ring.

culum and duodenal epithelial neoplasm has been reported $[4,5]$. In our case, gel immersion EMR was useful for treating early gastric cancer near the pyloric ring where it is difficult to fill the lumen with water and requires performing the procedure in a narrow space.

Endoscopy_UCTN_Code_TTT_1AO_2AG
Competing interests

The authors declare that they have no conflict of interest. 


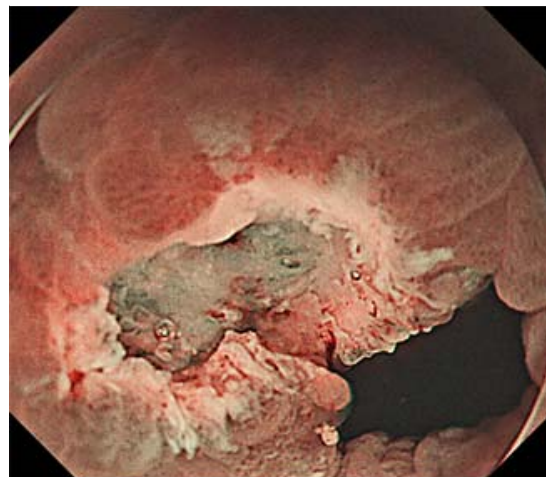

-Fig. 3 Endoscopic image of the ulcer after gel immersion endoscopic mucosal resection observed by narrow-band imaging.

Katsuyoshi Miura', Gota Sudo ${ }^{1,2} \odot$, Mitsunobu Saito ${ }^{1}$, Kazunori Onuma ${ }^{1}$, Yumemi Takada ${ }^{1}$, Atsushi Yawata ${ }^{1}$, Hiroshi Nakase ${ }^{2}$

1 Department of Gastroenterology and Hepatology, Hakodate Goryoukaku Hospital, Hakodate, Japan

2 Department of Gastroenterology and Hepatology, Sapporo Medical University School of Medicine, Sapporo, Japan

\section{Corresponding author}

\section{Gota Sudo, MD}

Department of Gastroenterology and Hepatology, Hakodate Goryoukaku Hospital, 3-38, Goryoukaku-cho, Hakodate 040-8611, Japan

Fax: +81-138-56-2695

gotasudo@gmail.com

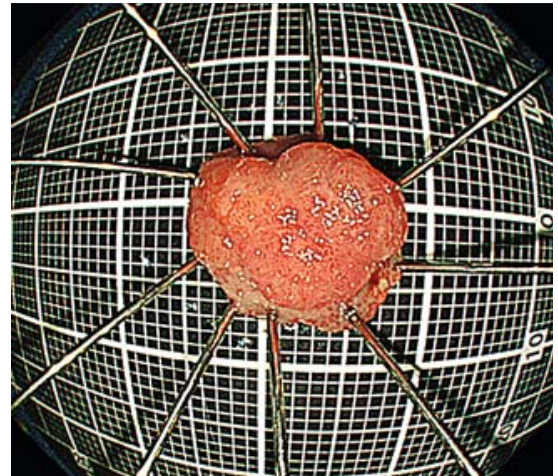

-Fig. 4 En-bloc resection specimen.

\section{References}

[1] Li DF, Lai MG, Yang MF et al. The efficacy and safety of underwater endoscopic mucosal resection for $\geq 10$-mm colorectal polyps: systematic review and meta-analysis. Endoscopy 2021; 53: 636-646

[2] Yamasaki Y, Uedo N, Akamatsu T et al. Nonrecurrence rate of underwater EMR for $\leq 20$-mm nonampullary duodenal adenomas: a multicenter prospective study (DUEMR study). Clin Gastroenterol Hepatol 2021: doi:10.1016/j.cgh.2021.06.043

[3] Iwagami H, Kanesaka T, Ishihara R et al. Underwater endoscopic mucosal resection for remaining early gastric cancer after endoscopic submucosal dissection. Endoscopy 2019; 51: E229-E230

[4] Kuwabara H, Chiba H, Tachikawa J et al. Efficacy of under-gel endoscopic mucosal resection method for colonic lesion extending into the diverticulum. Endoscopy 2021. doi:10.1055/a-1519-6642

[5] Yachida T, Kobara H, Tada N et al. Endoscopic mucosal resection under gel immersion for superficial nonampullary duodenal epithelial neoplasms. Endoscopy 2021. doi:10.1055/a-1544-7810

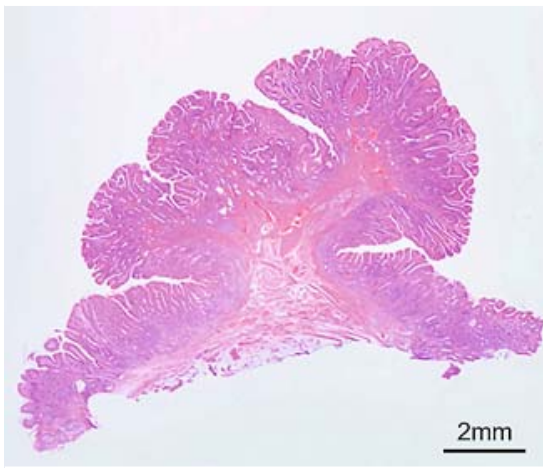

- Fig. 5 Histopathological image of the resected specimen demonstrating welldifferentiated intramucosal adenocarcinoma.

Bibliography

Endoscopy 2022; 54: E644-E645

DOI 10.1055/a-1730-4674

ISSN 0013-726X

published online 4.2.2022

(c) 2022. Thieme. All rights reserved.

Georg Thieme Verlag KG, Rüdigerstraße 14,

70469 Stuttgart, Germany

\section{ENDOSCOPY E-VIDEOS}

https://eref.thieme.de/e-videos

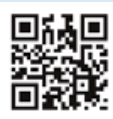

Endoscopy E-Videos is an open access online section, reporting on interesting cases and new techniques in gastroenterological endoscopy. All papers include a high quality video and all contributions are freely accessible online. Processing charges apply (currently EUR 375), discounts and wavers acc. to HINARI are available.

This section has its own submission website at

https://mc.manuscriptcentral.com/e-videos 